Institutions nationales ou interculturelles? Analyse de la programmation d'instituts culturels d'Europe centrale à Berlin et Paris à l'aube du XXI siècle

\title{
Gaëlle Lisack
}

\section{OpenEdition}

Journals

Édition électronique

URL : http://journals.openedition.org/ifha/8058

DOI : 10.4000/ifha.8058

ISSN : 2198-8943

Éditeur

IFRA - Institut franco-allemand (sciences historiques et sociales)

Édition imprimée

Date de publication : 31 décembre 2014

ISSN : 2190-0078

Référence électronique

Gaëlle Lisack, « Institutions nationales ou interculturelles ? Analyse de la programmation d'instituts culturels d'Europe centrale à Berlin et Paris à l'aube du XXIe siècle », Revue de l'IFHA [En ligne], 6 | 2014, mis en ligne le 31 décembre 2014, consulté le 19 avril 2019. URL : http://journals.openedition.org/ ifha/8058; DOI : 10.4000/ifha.8058

Ce document a été généré automatiquement le 19 avril 2019

CIFHA 


\title{
Institutions nationales ou interculturelles? Analyse de la programmation d'instituts culturels d'Europe centrale à Berlin et Paris à l'aube du XXI ${ }^{\mathrm{e}}$ siècle
}

\author{
Gaëlle Lisack
}

\section{NOTE DE L'ÉDITEUR}

Thèse de doctorat en cotutelle sous la direction de Jean-Paul Cahn et Olaf Schwencke, Université Paris Sorbonne et Freie Universität Berlin, soutenue le 28 mars 2013 à Berlin.

La Hongrie, la Pologne, la Slovaquie et la République tchèque ont fait le choix, après une remise en cause du principe même d'une politique culturelle étrangère au début des années 1990, de conserver leurs instituts culturels dans les capitales française et allemande et, le cas échéant, d'en créer. Ce travail étudie comment ces institutions conçoivent leur rôle dans les années qui précèdent et suivent l'entrée de leur pays dans l'UE (2000-2008) : se sont-elles fixé comme objectif de s'établir comme lieu du dialogue interculturel ou se concentrent-elles sur la présentation unilatérale de leur pays ? Si ces institutions aspirent à soutenir le dialogue interculturel, quelle stratégie ont-elles élaborée pour ce faire? Enfin, ces institutions s'inscrivent-elles dans la politique culturelle européenne?

D'une part ce travail propose une analyse actuellement inexistante de la programmation des instituts des pays du groupe de Visegrád à Paris et Berlin entre 2000 et 2008. D'autre part cette analyse a pour objectif de formuler, avec la prudence requise, des pistes de réflexion quant à l'orientation future des instituts culturels étudiés. 
Quatre composantes essentielles de la programmation des instituts culturels hongrois, polonais, slovaques et tchèques entre 2000 et 2008 ont été étudiées à partir des méthodes de la recherche sociale empirique : les objectifs, le contenu, la forme et la réception par le public. Pour ce faire, une attention particulière a été accordée aux objectifs élaborés en 2006 et 2008, à la programmation entre 2000 et 2008 et aux manifestations organisées par les instituts. Par ailleurs, une enquête menée auprès du public durant la saison 2006-2007 à Berlin et 2007-2008 à Paris et des interviews avec les directeurs des instituts culturels à l'été 2007 à Berlin et à l'été 2008 à Paris achèvent de fournir des indications précieuses pour le sujet étudié.

L'analyse retient l'hypothèse selon laquelle la particularité des instituts culturels nationaux à l'étranger réside dans la possibilité qu'ils représentent de constituer un lieu d'échange direct entre des représentants de différentes cultures. L'étude de la place accordée au dialogue interculturel dans les objectifs et la programmation est donc fondamentale pour répondre à la question de l'avenir de ces institutions.

Un retour sur l'histoire des instituts culturels met en lumière la particularité de ces institutions à la croisée de la politique et de la culture ainsi que l'évolution du concept de politique culturelle étrangère dans les pays qu'ils représentent au cours du vingtième siècle. L'analyse de la présentation de leur histoire par les instituts montre également la place très variable qu'ils accordent aux différentes périodes de leur passé dans l'identité qu'ils communiquent au début du vingt-et-unième siècle.

En 2006 comme en 2008, l'objectif principal des huit instituts culturels étudiés est la présentation (positive) de leur culture ou de leur pays dans son ensemble. Le dialogue et l'échange sont ponctuellement évoqués mais essentiellement comme instruments de présentation et non comme objectif en soi.

Dans les huit instituts étudiés la programmation entre 2000 et 2008 est essentiellement constituée de manifestations artistiques et offre, conformément aux objectifs annoncés, une grande variété de formats. Parmi eux la plupart sont, en soi, orientés vers la présentation. Les programmations présentent toutefois, à différents niveaux, des éléments dialogiques (coopérations avec des partenaires locaux, organisation de manifestations " hors les murs ", dans les institutions partenaires). La présence de ces éléments dans les programmations n'est pas due essentiellement à la volonté de participer au dialogue interculturel mais à celle d'améliorer l'image de soi.

L'analyse de la composition du public, de ses attentes et de sa perception des instituts culturels révèle que les instituts culturels polonais, slovaques, tchèques et hongrois à Paris et à Berlin ne peuvent en aucun cas être considérés comme des "ghettos" d'expatriés mais parviennent à renouveler leur public et à attirer des personnes d'horizons culturels divers. Cependant, le dialogue interculturel ne s'est pas imposé auprès des visiteurs comme caractéristique fondamentale des instituts.

Enfin une coordination de la programmation des instituts culturels avec l'orientation de la politique culturelle européenne n'est pas perceptible. Au niveau européen s'est établie une conception élargie de la culture qui comprend une composante sociétale. Mais l'entrée des pays du groupe de Visegrád dans l'UE n'a pas été l'occasion d'ancrer une telle dimension ni un caractère européen dans la programmation de leurs instituts culturels dans les capitales française et allemande. En 2008, un renoncement au caractère national de leur programmation au profit d'une dimension européenne ou internationale n'est pas à l'ordre du jour. 
Ainsi, les instituts culturels du groupe de Visegrád à Paris et Berlin ont pris congé au début des années 2000 d'une présentation culturelle exclusivement unilatérale. Cependant, les éléments dialogiques de leur programmation, qui pourraient être bénéfiques au dialogue interculturel, sont inégalement présents. De plus, la motivation première pour leur insertion dans la programmation repose surtout sur la volonté de présenter une image positive, moderne et variée du pays à un public le plus large possible et n'accorde qu'une place secondaire au dialogue interculturel. Si les éléments dialogiques sont renforcés et approfondis, ces institutions pourraient devenir dans les prochaines années des porteurs du dialogue interculturel européen. Mais il faut pour cela qu'ils se distancient de leurs objectifs premiers de présentation et de promotion et confèrent à leur programmation un caractère européen.

\section{AUTEUR}

\section{GAËLLE LISACK}

(Université Paris-Sorbonne/Freie Universität Berlin) 